\title{
Development of the Thermoacoustic Refrigerator System Using a Stack made of some Stainless Steel Mesh and a Hot Heat Exchanger
}

\author{
Haris S Dyatmika ${ }^{1}$, Wahyu Nur Achmadin ${ }^{1 *}$, Prastowo Murti $^{1}$, I. Setiawan ${ }^{1}$, Agung B S \\ Utomo $^{1}$
}

${ }^{1}$ Department of Physics, Universitas Gadjah Mada,Bulaksumur BLS 21, 55281, Yogyakarta

Received: 16 June 2015, Revised: 24 July 2015, Accepted: 30 July 2015

\begin{abstract}
In order to develop and increase the performance of a thermoacoustic refrigerator system, a research has been conducted. In this research a PVC cylindrical pipe (diameter of $5.5 \mathrm{~cm}$ and length of $80 \mathrm{~cm}$ ) as a tube resonator, a loudspeaker as a sound source, some stainless steel mesh as a stack and a hot heat exchanger were arranged to be a thermoacoustic refrigerator system. The results show the influence of cooling power by utilizing some stainless steel mesh stack, the power of the utilized sound, and a hot heat exchanger on the performance of the thermoacoustic system. We expected to construct a thermoacoustic refrigerator system, which has an optimally performance, by using some stainless stell mesh as stack and a hot heat exchanger.
\end{abstract}

Keywords: mesh, stainless steel, and thermoacoustic

\section{INTRODUCTION}

The availability of non-freon cooling systems (AC) is clearly needed since most of the cooling systems used now still using freon as their cooling substance. Therefore, the development of non-freon cooling systems as the alternative cooling systems that are not harmful for the environment is extremely important. One of non-freon cooling systems is thermoacoustic refrigerator systems. Beside the advantage of being a non- harmful for the environment, non-freon cooling systems use inexhaustible cooling substance, such as air or noble gases, thermoacoustic refrigerator system uses sound wave in the cooling process.

A simple design of thermoacoustic system has been made by Ikhsan et al by using PVC (poly-vinyl chloride) material as a resonator pipe, stack made of papers, or photographic films [1-2]. The parameters that were observed such as the effect of intensity and frequency of the sound wave, as well as the length and diameter of the resonator towards the thermoacoustic system perfomance [3-8]. Most of the previous researches have used a parallel stack, while this research have used a random porousity stack which is made of some stainless steel mesh. The previous researches have been successfully done by using stainless steel stacks [9-11], or by using non-metalic stack [12].

\section{THEORY}

Figure 1 shows the thermoacoustic cycle. The acoustic wave causes gas package to move to the left and will increase the gas pressure, and then the gas package will be compressed. The heat on the compressed gas is higher than that of on the stack's wall, hence the gas package will release the heat to the stack and then the volume of the gas package decreases. When the wave continues to cycle, the gas package will move back to the right, expand and has a lower heat that caused by lowering the pressure in the right space, so the gas will absorb the heat from the stack wall for expanding. This cycle will repeat again and again, and give heat transfer effect from the right reservoir to the left one [13]. The reservoir that has the lower heat is called a cold reservoir, while the one that has a higher heat is called a hot reservoir. 

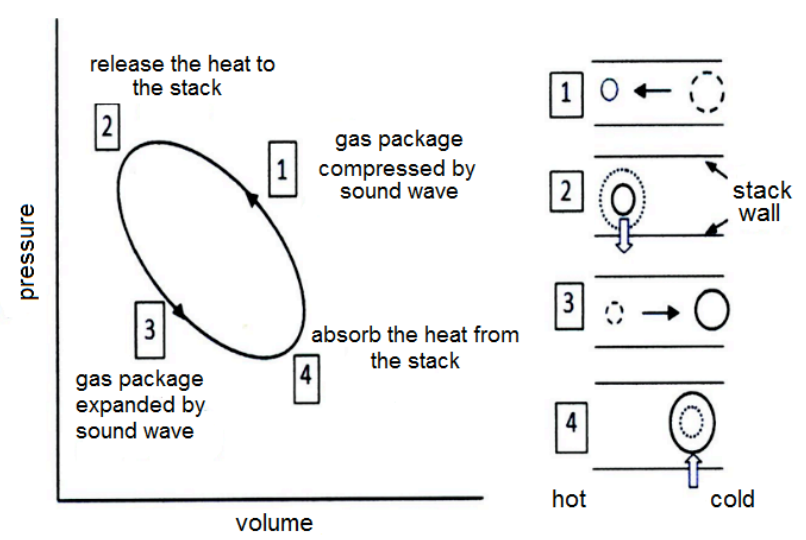

Figure 1. The $P-V$ graph that shows four steps of thermoacoustic cooler cycle [13].

\section{EXPERIMENTAL METHOD}

The components of thermoacoustic device were a loudspeaker type CUBIG (it has diameter of 10 inches, impedance of $4 \mathrm{ohm}$, power of 400 watt) in a covered box that was connected with a digital audio function generator (AFG) GFG-8016G (with $1 \mathrm{~Hz}$ precision) and an amplifier BELL M-9000 as a sound system (Figure 3).

The temperature detection systems used were four temperature sensors of LM-35 (with $0.1{ }^{\circ} \mathrm{C}$ precision) that for two sensors were placed at each reservoir and at the hot heat exchanger. The hot heat exchanger used was made of copper leaves with small pipes as water pipe [14], as can be seen in Figure 2(b).

The resonator tube used was made of PVC pipe $(5.5 \mathrm{~cm}$ in diameter) $80 \mathrm{~cm}$ in length which consists of three parts, i.e. $14 \mathrm{~cm}, 11 \mathrm{~cm}$ and $54 \mathrm{~cm}$. The hot heat exchanger was placed in between of the $14 \mathrm{~cm}$ and $11 \mathrm{~cm}$ resonator pipes. The stack used in this research was placed in $11 \mathrm{~cm}$ resonator pipe. The use of resonator made from PVS in this research was similar to the research conducted by Ma'rifah [15].
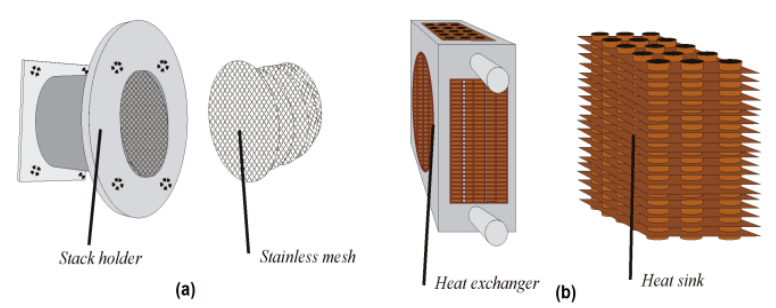

Figure 2. Thermoacoustic device components: (a) the arrange of stainless steel mesh leaves, and (b) hot heat exchanger and water valves.

In this research, the stack was made from stainless steel mesh that were arranged compactly along $L$, as shown in Figure 2(a). Arrangement mesh leaves were varied by $L=4 \mathrm{~cm}, 4.5 \mathrm{~cm}, 5 \mathrm{~cm}, 5.5$ $\mathrm{cm}, 6 \mathrm{~cm}, 6.5 \mathrm{~cm}$, and $7 \mathrm{~cm}$.

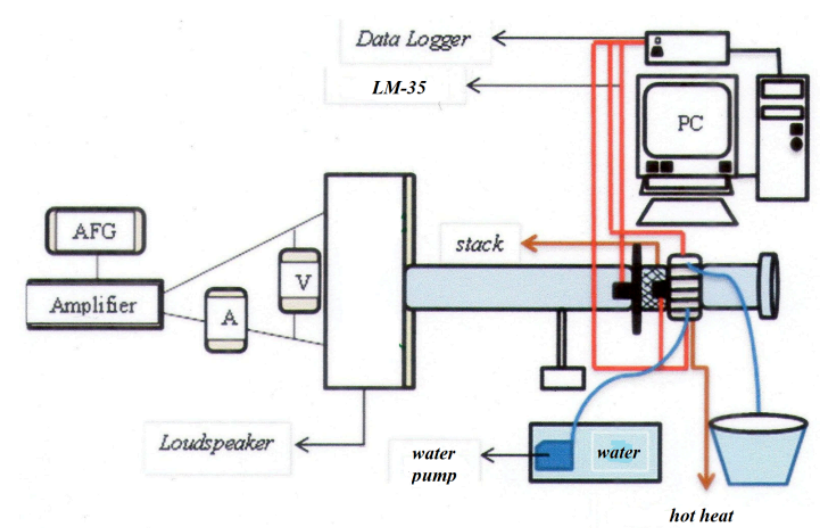

Figure 3. Thermoacoustic set-up device

\section{RESULTS AND DISCUSSION}

In this research, we have used the optimal size of the stack in this thermoacoustic system that was the mesh of \#18 with the length $5 \mathrm{~cm}$ [9].

The performance of thermoacoustic device can be seen in its cooling power and how big its temperature reduction that can be achieved by the cold reservoir. The cooling rate and the heating process in the resonator tubes shows that there are significantly temperature change on the cool and hot reservoirs. Figure 4 shows the temperature on both reservoirs at various input potential of the loudspeaker. Overall, the changes of the temperature for all variation of the potential is showed by two curves, i.e. the cooling point line $(T \mathrm{c})$ and the heating point $(T h)$.

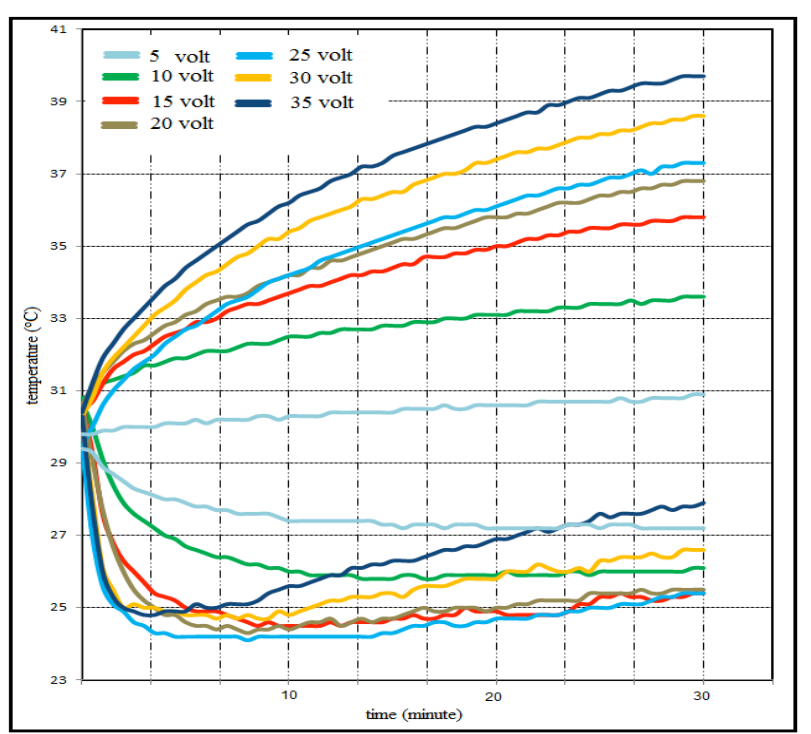

Figure 4. The relation between temperature towards time at various input potential.

In general, the greater is the acoustic wave power, the quicker process of the heating and the cooling in the reservoirs. It can be seen from Figure 4 that all of the curves showing the cooling points 
which decrease at the beginning with different slopes. This curve behaviour shows the relationship between the power of the wave and the cooling process rate aforementioned above.

At the beginning, the heat from the hot reservoir have not back propagated to the cold reservoir. However, the greater of the power is applied, the quicker of the heating flows into the cold reservoir due to reverse heat flow from hot reservoir. It could be prevented the reversing heat by reducing the heat in the hot reservoir, i.e. by attaching a hot heat exchanger in hot reservoir.

Figure 5 shows the thermoacoustic curves after attaching a hot heat exchanger. It has affected the cooling and heating rates of reservoirs. The hot heat exchanger is made of copper which has a high heat capacitance and a great thermal conductivity. So it is clearly able to absorb some heat from hot reservoir and release the heat to environment (out of the system). The cooling substance for hot heat exchanger for absorbing heat is water [16]. When the water is applied, the temperature in the hot reservoir relatively decreasing. It is occurred because of the ability of the water absorbing the heat, and then releasing it to the environment. Hence, there is no heat moving back to the cold reservoir.

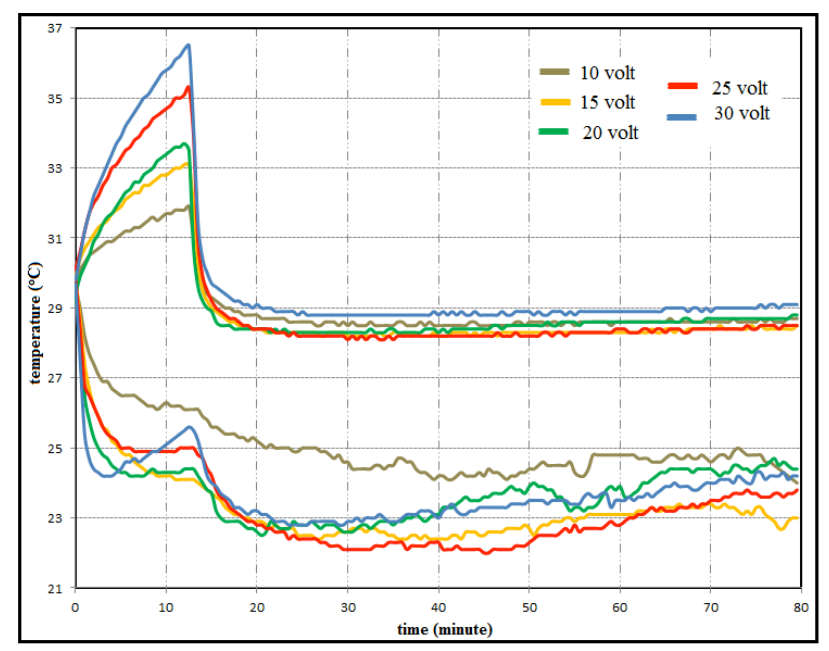

Figure 5. The temperature curves after the hot heat exchanger attachment towards time at various input potential

The decrease of the hot reservoir temperature is a direct process which is caused by the heat absorption by water in the hot reservoir. On the other hand, the temperature decreasing in the cold reservoir is an indirect process which is caused by pumping the heat from the cold to the hot reservoirs.

From the cool part of Figure 6 (blue line), it can be seen that the hot heat exchanger capable to decrease the temperature of the reservoir. At the first 1800 seconds, before water have not been flowed yet through the hot heat exchanger, the temperature in the cold reservoir goes down but then temperature will rise due to the reverse heat flowing.

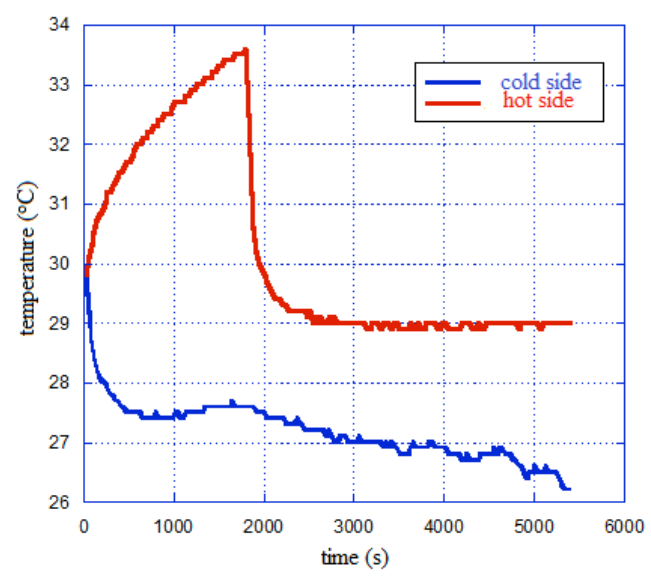

Gambar 6. The temperature changes of the thermoacoustic device with the flowing water hot heat exchanger

After 1800 seconds, or when the temperature in cold reservoir rises, the water is flowed through the hot heat exchanger as a result the temperature decease again. This clearly shows that the hot heat exchanger works.

\section{CONCLUSION}

The results show that the use of the stack made of some stainless steel mesh \#18 with the length of $5 \mathrm{~cm}$ at frequency of $105 \mathrm{~Hz}$ gave the heat transfer effect. Then by flowing water passing through the hot heat exchanger has been proved to be able to reduce the temperature on hot reservoir directly, and then reduce some reverse heat flowing from the hot to cool reservoirs.

The further development of this research can be focused on the optimization of the parameters that affects on the thermoacoustic refrigerator system performance.

\section{ACKNOWLEDGMENT}

The authors are gratefully thanks to the Atomic and Nuclear Physics Laboratory, Department of Physics, and the Faculty of Mathematics and Natural Sciences, Gadjah Mada University for the financial supporting.

\section{REFERENCES}

[1] I. Setiawan et al., Design of thermoacoustic device as conditioning and heating air simultaneously, Research report inter- 
disciplinary, Universitas Gadjah Mada, Yogyakarta, Indonesia, 2005.

[2] I. Setiawan et al., Design of thermoacoustic device as heat pump, Sigma, 10, 25-33, 2007.

[3] M. S. Elyanita, I. Setiawan, and A. B. S. Utomo, Influence of variable frequency and stack position made of cardboard on the temperature variable on the thermoacoustic system, Jurnal Fisika Indonesia No. 33, 11, 2007.

[4] Romdhiah, I. Setiawan, dan A. B. S. Utomo, The influence of location stack and sound wave frequency on the temperature difference on the thermoacoustic system with stack made of glass-film, Jurnal Fisika Indonesia No. 31, 10, 2006.

[5] Zulheldi, I. Setiawan dan A. B. S. Utomo, The influence of sound intensity, distance of location stack and diameter tube resonator on the thermoacoustic device, Jurnal Fisika Indonesia No. 31, 10, 2006.

[6] D. Sampurna, I. Setiawan, dan A. B. S. Utomo, Experimental study to determine the effect of tube diameter resonator cylindrical on the performance of thermoacoustic device, Jurnal Fisika Indonesia No. 33, 11, 2007.

[7] I. Setiawan, Mitrayana, A. B. S. Utomo, Development of thermoacoustic refrigerator environmentally friendly using two stacks, Proccedings $7^{\text {th }}$ Basic Science National Seminar (20 Februari, 2010, Universitas Brawijaya, Malang, Indonesia), ISBN 978-60296393, 2010.

[8] I. Setiawan et al., Experimental study on the influence of the porosity of parallel plate stack on the temperature decrease of a thermoacoustic refrigerator, Journal of Physics: Conference Series 423, 012035, IOP Pub, 2013.

[9] P. Murti, The influence of frequency and tortuous stack length to temperature differences in performance of thermoacoustic refrigerator, Undergraduate Thesis, Universitas Gadjah Mada, Yogyakarta, Indonesia, 2013.

[10] W. N. Achmadin, Study experiment to know the influence of porous size and length of stack substance with the existence of a hot heat exchanger respect to the performance of cold thermoacoustics device, Undergraduate Thesis, Universitas Gadjah Mada, Yogyakarta, Indonesia, 2013.

[11] H. S. Dyatmika, A thermoacoustics system with non-parallel pore stack in a various speaker voltage, Undergraduate Thesis, Universitas Gadjah Mada, Yogyakarta, Indonesia, 2013.

[12] I. Farikhah et al., Thermoacoustic design using stem of goose down stack, AIP Proc. Int. Conf. $19^{\text {th }}$ Symposium on Nonlinear Acoustics (May 21-24, 1012, Tokyo, Japan), 2012.

[13] D. A. Russell and P. Weibull, Tabletop thermoacoustic refrigerator for demonstration, Am. J. Phys. 70, 1231-1233, 2002.

[14] P. Asmara, The influence of copper pipe containing flowing liquid as a heat exchanger on the thermoacoustic device, Undergraduate Thesis, Universitas Gadjah Mada, Yogyakarta, Indonesia, 2011.

[15] L. K. Ma'rifah, The optimization of tube diameter resonator cylindrical and loudspeaker power against decreasing the temperature on the thermoacoustic refrigerator system, Undergraduate Thesis, Universitas Gadjah Mada, Yogyakarta, Indonesia, 2009.

[16] A. Pebriarti, The influence of various density of the liquid on the heat exchanger against the temperature decrease on thermoacoustic device, Undergraduate Thesis, Universitas Gadjah Mada, Yogyakarta, Indonesia, 2011. 